\title{
Investigation of Process Parameters Optimization in Die - Sinking Edm to Improve Process Performance Using Taguchi Technique
}

\author{
Dr.T.Vijaya Babu ${ }^{1}$, Dr .J.S Soni ${ }^{2}$, \\ ${ }^{I}$ Professor, Department of Mechanical Engineering, Vardhaman College of Engineering, Shamshabad, \\ Hyderabad, India \\ 2., Professor \& Principal, Bharat Institute of Engineering and Technology, Ibrahimpatnam, Hyderabad
}

\begin{abstract}
Electrical discharge machining (EDM) is a well-established machining option for manufacturing geometrically complex or hard material parts that are extremely difficult-to-machine by conventional machining processes. The non-contact machining technique has been continuously evolving from a mere tool and dies making process to a micro-scale application machining alternative attracting a significant amount of research interests. This involves optimization of the process parameters by relating these with the performance measures maximizing the MRR, while minimizing the TWR and yielding the desired SR. The monitoring and control of the EDM process will be carried out by the identification and regulation of adverse arcing occurring during the sparking process. Wire electro discharge machining (WEDM) is a modification of electro discharge machining $(E D M)$ which has been widely used for long time for cutting punches and dies, shaped pockets and other machine parts of Technology of the WEDM process is based on the conventional EDM sparking phenomenon, utilizing the widely accepted non contact technique of material removal with a difference that spark is generated at the wire and work piece gap. Evolution of WEDM made drastic changes in the area of precision machining with highest degree of dimensional accuracy and surface finish. The present objective is to optimize the process parameters to enhance the performance parameters. The orthogonal array of experiments formed on the basis of relevant Taguchi technique will be conducted based on different electrode materials and work piece materials. The objective of these experiments to give relation between process and performance parameters for different machinability conditions and to improve the efficiency of the process.
\end{abstract}

Keywords: Electrical Discharge Machining (EDM), Die-sinking discharge machining , process parameters, Taguchi method.

\section{Introduction}

Electric Discharge Machining (EDM) is a controlled material removal technique where by high frequency electric spark are used to erode the work piece which takes a shape corresponding to that of tool electrode. The cutting tool is made from electrically conductive material such as copper or graphite. The electrode made to the shape of cavity required, and the work pieces required are both submerged in a dielectric fluid which is a nonconductor of electricity. A servomechanism maintains a gap between the electrode and the work, preventing them from coming into contact with each other. The ignition of the discharge is initiated by a high voltage, overcoming the dielectric breakdown strength of the small gap. A channel of plasma is formed between the electrodes and develops further with discharge duration. As the metal removal per discharge is very small, discharges should occur at high frequencies (103-106 Hz). For every pulse, discharge occurs at a single location where the electrode materials are evaporated and/or ejected in the molten phase. As a result, a small crater is generated both on the tool electrode and work piece surfaces. Removed materials are cooled and resolidified in the dielectric liquid forming several hundreds of spherical debris particles, which are then flushed away from the gap by the dielectric flow.

\section{Literature Survey}

A significant amount of work has been focused on ways of yielding optimal EDM performance measures of high metal removal rate (MRR), low tool wear rate (TWR) and satisfactory surface roughness (SR). J.S. Soni and G. Chakraverti [1] have explained the migration of material elements between the electrode and work piece. The work piece used for this investigation is high carbon chromium die steel ( $\mathrm{T} 215 \mathrm{Cr} 12)$. They also studied the scanning electron microscope (SEM) investigation on changes in the chemical composition of resolidified layers of the tool and the work piece as well as debris. The changes in chemical composition often remain confined to within resolidified layer which was supported by others [2]-[3]. O.A. Abu Zeid investigated the role of voltage, pulse-off-time in the electro discharge machined AISI T1 high speed steel [4]. He found that the MRR is not very sensitive to off-time changes at a low pulse-on-time corresponding to finish machining. Volumetric electrode wear has been found to be less with shorter off-times when finish machining but is independent of the off-time and direction of flushing. L.C. Lee, and L.C. Lim investigated the surface 
transformation and damage in AISI O1, A2, D2, and D6 steels after EDM [5]. According to them the electrical discharge machined surface of all the tool steels generally consists of three distinct layers the out most white layer, an immediate layer and the unaffected parent layer. Pandey and Jilani [6] presented a thermal model on plasma channel growth and thermally damaged surface layer.They also drew the same conclusion that the EDMed surface has three distinct zones as that of Lee and Lim. Lim et al. [7] provided a review on the metallurgy of EDMed surface, which is dependent on the solidification behavior of the molten metal after the discharge cessation and subsequent phase transformation. The thickness of the recast layer formed on the work piece surface and the level of thermal damage suffered by the electrode can be determined by analyzing the growth of the plasma channel during sparking. EDMed surface has a relatively high micro hardness, which can be explained by the emigration of carbon from the oil dielectrics to the work piece surface forming iron carbide in the white layer [8]. Electrical discharge machining (EDM) is an important manufacturing process for machining hard metals and alloys [9]. This process is widely used for producing dies, molds, finishing parts for aerospace, automotive, and surgical components. The process is capable of getting required dimensional accuracy and surface finish by controlling the process parameters [10]. Rebolo [11] investigated the effect of EDM parameters on material removal rate and surface quality. From the experiments it has been concluded that for positive polarity the edm samples presents a normal behavior with increasing mrr when machining energy is increased. S.H Lee [12] had studied the operating parameter on tungsten carbide and effectiveness of edm process is evaluated in terms of surface quality and mrr. He found out that mrr increases with increase in open voltage but TWR and surface roughness increases with increase in open circuit voltage. I. Puertas[13] had analyzed the influence of current intensity, pulse time and duty cycle over output responses such as S.R and MRR. In the case of Ra parameter the most influencing factor was current followed by pulse on time. In order to obtain surface finish low values to be used for current intensity and pulse on time. M. Kiyak [14] had studied the influence of EDM parameters on surface roughness for machining AISI P20 tool steel. Parameters such as current, pulse time and pulse off time are selected. It has been observed that the surface roughness increases with increase in current and pulse on time. C. J Luis [15] has conducted the study to analyze the influence of pulse time, duty cycle, voltage and flushing pressure over silicon carbide work piece. It has been seems that current and voltage has significant influence on MRR. Rao conducted the 27 experiments by varying EDM parameters such as current, pulse on time and duty factor. The output responses such as S.R, MRR and hardness are assessed. Rao observed that the MRR and S.R increases with increase in current and duty factor. But when pulse on time increases MRR and surface roughness decreases. Hardness value increases as the current value increases from $5 \mathrm{~A}$ to $10 \mathrm{~A}$ and then decreases as current increases from 10A to $15 \mathrm{~A}$. Rajmohan conducted the study on the 304 stainless steel and investigated the influence of pulse on time, pulse off time, voltage and current affecting MRR. The current and pulse off time are the significant factor affecting MRR in edm. The present work is concentrated on M300 which is extremely used in aerospace, gyroscope etc.

\section{A. Selection of work piece material and electrode material}

\section{Experimental Details}

The work piece material used for the study is M300 steel and tool material is copper tungsten. The copper tungsten was selected because it is subjected to low wear compared to copper.

\section{B. Identifying the EDM process parameters and fixing the levels}

On the basis of the literature survey $[4,8]$ and previous work experience, it was concluded that the voltage, current, pulse on time has significant effect on surface roughness. The working range of process parameters selected is shown in Table 1.

\begin{tabular}{|c|c|c|c|}
\hline Levels & $\mathbf{l}$ & $\mathbf{2}$ & $\mathbf{3}$ \\
\hline Voltage & 80 & 120 & 160 \\
\hline Current & 0.5 & 1 & 1.5 \\
\hline Pulse on time & 0.8 & 1.6 & 3.2 \\
\hline
\end{tabular}

\section{Selection of Orthogonal array}

The selection of $\mathrm{OA}$ is based upon the number of factors and levels corresponding to each of the factors. The degree of freedom for each of the factor is 2 and therefore the total dof obtained is 6 (i.e., $3 \times 2=6$ ). The selected OA degree of freedom must be greater than the total dof of all the factors. The dof for OA is 8(i.e., number of experiments-1). Hence L9 is considered for the study. The selected OA is presented on the following Table 2 .

\begin{tabular}{|l|l|l|l|}
\hline Run & Voltage & Current & Pulse on time \\
\hline 1 & 80 & 0.5 & 0.8 \\
\hline 2 & 80 & 1 & 1.6 \\
\hline
\end{tabular}




\begin{tabular}{|l|l|l|l|}
\hline 3 & 80 & 1.5 & 3.2 \\
\hline 4 & 120 & 0.5 & 1.6 \\
\hline 5 & 120 & 1 & 3.2 \\
\hline 6 & 120 & 1.5 & 0.8 \\
\hline 7 & 160 & 0.5 & 3.2 \\
\hline 8 & 160 & 1 & 0.8 \\
\hline 9 & 160 & 1.5 & 1.6 \\
\hline
\end{tabular}

\section{Conduct the experiments as per the selected $O A$}

The cylindrical work piece of maraging steel M300 material of $25 \mathrm{~mm}$ diameter and thickness of $1.8 \mathrm{~mm}$ are selected for the experiments. The electrode used for the experiment is the copper tungsten of $10 \mathrm{~mm}$ in diameter .The Agie Charmilles edm machine of Roboform 200 is used for the study of EDM parameters affecting the surface roughness. The work piece is mounted on the fixture which has the same dimension of the samples. EDM-30 is used as die-electric fluid.

\section{E. Record the performance measures}

The machining performance was evaluated surface roughness. The surface roughness is referred as roughness or smoothness of a given surface. In this study, it was measured in terms of roughness average (Ra), which is an arithmetic average of peaks and valleys of a work piece surface measured from the centerline of evaluation length. It was measured by TALYSURF CLI 2000 surface roughness tester. The machining performance measures SR were evaluated for all the conditions and presented.

\begin{tabular}{|l|l|l|l|l|}
\hline Run & Voltage & Current & Pulse on time & Surface roughness \\
\hline 1 & 80 & 0.5 & 0.8 & 0.147 \\
\hline 2 & 80 & 1 & 1.6 & 0.193 \\
\hline 3 & 80 & 1.5 & 3.2 & 0.210 \\
\hline 4 & 120 & 0.5 & 1.6 & 0.106 \\
\hline 5 & 120 & 1 & 3.2 & 0.220 \\
\hline 6 & 120 & 1.5 & 0.8 & 1.400 \\
\hline 7 & 160 & 0.5 & 3.2 & 0.135 \\
\hline 8 & 160 & 1 & 0.8 & 1.73 \\
\hline 9 & 160 & 1.5 & 1.6 & 0.156 \\
\hline
\end{tabular}

\section{F. Find the optimum condition for the Surface roughness}

Taguchi method of design of experiment is to reduce the number of experiment, yet cover the entire parameter space with the help of special design of orthogonal array. The results of such experiments are then transformed into signal to noise ratio $(\mathrm{S} / \mathrm{N})$ ratio to measure the deviation of the performance characteristics from the desired values. The performance characteristic for the surface roughness is chosen as the smaller the best.

$\mathrm{S} / \mathrm{N}=-10 \log ;\left[\frac{1}{n} \sum_{i=1}^{n}\left(y_{i}^{2}\right)\right]$

Where $\mathrm{n}$ is the number of measurements in a trial and yi is the measured value in the trial.

\section{Results And Discussions}

After the experimental procedure, response factors surface roughness of machined surface was calculated from the observed data. Then a statistical analysis was performed using MINITAB 16 software and the signal to noise ratio values of surface roughness are tabulated in Table 4.

\begin{tabular}{|c|c|c|c|c|c|}
\hline Run & Voltage & Current & Pulse on time & Surface roughness & S/N ratio of SR \\
\hline 1 & 80 & 0.5 & 0.8 & 0.147 & 16.65 \\
\hline 2 & 80 & 1 & 1.6 & 0.193 & 14.28 \\
\hline 3 & 80 & 1.5 & 3.2 & 0.210 & 13.55 \\
\hline 4 & 120 & 0.5 & 1.6 & 0.106 & 19.44 \\
\hline 5 & 120 & 1 & 3.2 & 0.220 & 13.15 \\
\hline 6 & 120 & 1.5 & 0.8 & 1.400 & 2.922 \\
\hline 7 & 160 & 0.5 & 3.2 & 0.135 & 17.34 \\
\hline 8 & 160 & 1 & 0.8 & 1.73 & 4.760 \\
\hline 9 & 160 & 1.5 & 1.6 & 0.156 & 16.13 \\
\hline
\end{tabular}

The $\mathrm{S} / \mathrm{N}$ ratio could be the effective representation to find the significant parameter by evaluating the minimum variance. By applying the above equation, the $\mathrm{S} / \mathrm{N}$ ratio values of machining performance for each experiment of L9 OA can be calculated for the SR values. 
The main effect values are plotted in Figure. 2 for the voltage, current and pulse on time respectively. The main effects plot shows the influence of each level having major contribution are selected from the plot and are the optimized levels for the particular factor. The ANOVA is a statistically based, objective decision making tool for detecting any difference in the average performance of groups of items tested. ANOVA helps in formally testing the significance of all main factors and their interactions by comparing the mean square against an estimate of experiment at specific confidence levels. The $\mathrm{P}$ value reports the significance level percentage $(\%)$ is defined as the significance rate of process parameters on the output responses. The optimal level of the machining parameters is the level with the lowest $\mathrm{S} / \mathrm{N}$ ratio value. Based on the analysis of $\mathrm{S} / \mathrm{N}$ ratio, the optimal machining performance for the surface roughness is obtained at a voltage of $80 \mathrm{~V}$ (level 1), current of $0.5 \mathrm{~A}$ (level 1) and pulse on time of $1.6 \mu$ s (level 2).

\section{Conclusion}

In this study the influence of the process parameters and optimization of M300 steel in the die sinking EDM was studied by using Taguchi L9 orthogonal array method. From the results, it was found that voltage, current and pulse on time has been found to play significant role in EDM operations. Also it was found that the for the lower surface roughness the optimum levels for voltage, current and pulse on time is A1-B1-C2.The level of importance of the machining parameters and their individual contributions on the surface roughness is determined by using analysis of variance (ANOVA). The parameter current was found to be the most effective on the surface roughness followed by the voltage and pulse on time.

\section{References}

[1]. J.S. Soni, G. Chakraverti, "Experimental investigation of migration of material during EDM of die Steel (T215Cr12)," 1994. pp.5158.

[2]. Koshy George, P.K. Philip and Geddam A, "Hardening of surface layers using electrical discharge techniques," Proc. Conf. 11th AIMTDR, IIT, MADRAS, 1981, p. 315

[3]. A. Gandadhar ,M.S. Shunmugam and P.K Philip, "Surface modification in electro discharge techniques with a powder compact tool electrode," Wear, Vol. 143,No 1,1991, p.45.

[4]. $\quad$ O.A. Abu Zied, "The role of voltage pulse off-time in the electro discharge machined AISI T 1 high- speed steel," J. of Mat Process Technol. 61, 1996, pp.287-291

[5]. L.C. Lee, L.C. Lim, V. Narayanan and V.C Venkatesh, “Quantification of surface damage of tool steel after EDM,” Vol. 28, No 4, 1988, pp. 359- 372.

[6]. S.H. Lee, X.P. Li, "Study of the effect of machining parameters on the machining characteristics in electric discharge machining of tungsten carbide," Journal of Matl. Processing Technology, 115, 2001, pp.344-358.

[7]. L.C. Lim, L.C. Lee, Y.S. Wong , H.H Lu, "Solidification microstructure of electro discharged machined surface of tool steels," Mater. Sci. Technol,7, 1991, pp. 239-248.

[8]. J.P. Kruth, L. Stevens, L. Froyen, B. Lauwers, "Study of the white layer of a surface machined by die- sinking electro discharge machining," Ann.CIRP, 44, 1,1995, pp. 169-172.

[9]. G. Krishna Mohana Rao, "Influence of the machining parameters on electric discharging machining of maraging steels," Proceeding of the world congress of engineering, vol.II, pp.978-988, July 2008.

[10]. A. M. Nikalje, "Influence of parameters and optimization of EDM performance measures on MDN 300 steel using Taguchi method," International journal of manufacturing technology, vol.69, pp. 41-49,April 2013.

[11]. J. C. Rebolo,"An experimental study on electro discharge machining and polishing of high strength copper-berlliyum alloys, "Journals of material processing technology,vol.103, pp. 389-397,Dec 2000.

[12]. S. H. Lee," Study of the effect of machining parameters on the machining characteristics in electrical discharge machining of tungsten carbide," Journal of material processing technology,vol.115, pp. 344-358,Sep 2001

[13]. I. Peuratos, “Analysis of the influence of EDM parameters on the surface quality, MRR and EW of WC-Co,” Journals of material processing technology,vol.153,pp.1026-1032,2004.

[14]. M. Kiyak, "Examination of machining parameter on surface roughness in EDM of tool steel," Journals of material processing technology, vol.191, pp.141-144, 2007.

[15]. C. J Luis, “ Material removal rate and electrode wear study on the EDM of silicon carbide," Journals of material processing technology,vol.164,pp.889-896,2005. 